\title{
The Use of Media and Technology in the Classroom
}

\author{
Mario Pezzino \\ School of Social Sciences \\ University of Manchester \\ Email: Mario.Pezzino@manchester.ac.uk \\ Edited by Caroline Elliott, Aston University
}

Published May 2017

Printable PDF

This chapter is a guide to the most popular forms of technological innovation in higher education teaching, with a particular focus on economics. We shall point out where the technologies' features align with students' preferences. We shall also point out possible issues, pitfalls and problems. In Section 2 we discuss the use of lecture recording. In Section 3 we discuss the use of media files (for example visuals, audio files, video clips, online media) embedded in classes. In Section 4 we describe the use of personal response systems (sometimes called clickers) that allow students to answer multiple choice questions interactively and anonymously during lectures. In Section 5 we describe the use of mathematical software to produce dynamic images and to create adaptive online assessment. Finally, in Section 6 we consider the use of social media to communicate and interact with students.

\section{Introduction}

Thanks to recent technological advancements, reduced costs and ease of access to online digital media, instructors in higher education have been increasingly adopting forms of media and technological innovation in their curriculum. Nowadays, instructors can embed digital media in their teaching, instantly and remotely communicate with students via social media or discussion boards provided in virtual learning environments, create videos and record lectures to be shared online, or test students' preparation online. Similarly, most students now possess devices that allow them to access, anywhere and often at negligible cost, digital resources provided by module convenors.

For instructors considering various forms of teaching innovation, it is important to have an idea of students' own preferences regarding technology in the classroom. In summer 2013 the nonprofit organisation Jisc released a Student Innovation Competition[1] calling for student-led projects to explore novel uses of technology in learning. Interestingly, the submissions provided very useful insights regarding what students really want[2] from technology in higher education. Two main areas could be highlighted. First, personalised learning; specifically, students seemed keen to personalise lectures (for example communicating and interacting-possibly anonymously — with instructors during lectures), tracking their learning progress online and have 
effective tools for revision. A second area was networking; students were interested in platforms that would connect them with students in different years and with those studying the same subject at other universities.

The use of technological innovation applied to teaching should also be considered when designing the whole curriculum. According to the curriculum design cycle[3] a curriculum should meet the changing needs of students and employers. The use of technology as part of the curriculum design would include ways to improve communication with stakeholders to facilitate discussion and collaboration, to capture and record information, to increase consistency both in terms of the learner experience and quality assurance.

\section{Figure 1: the curriculum design circle}

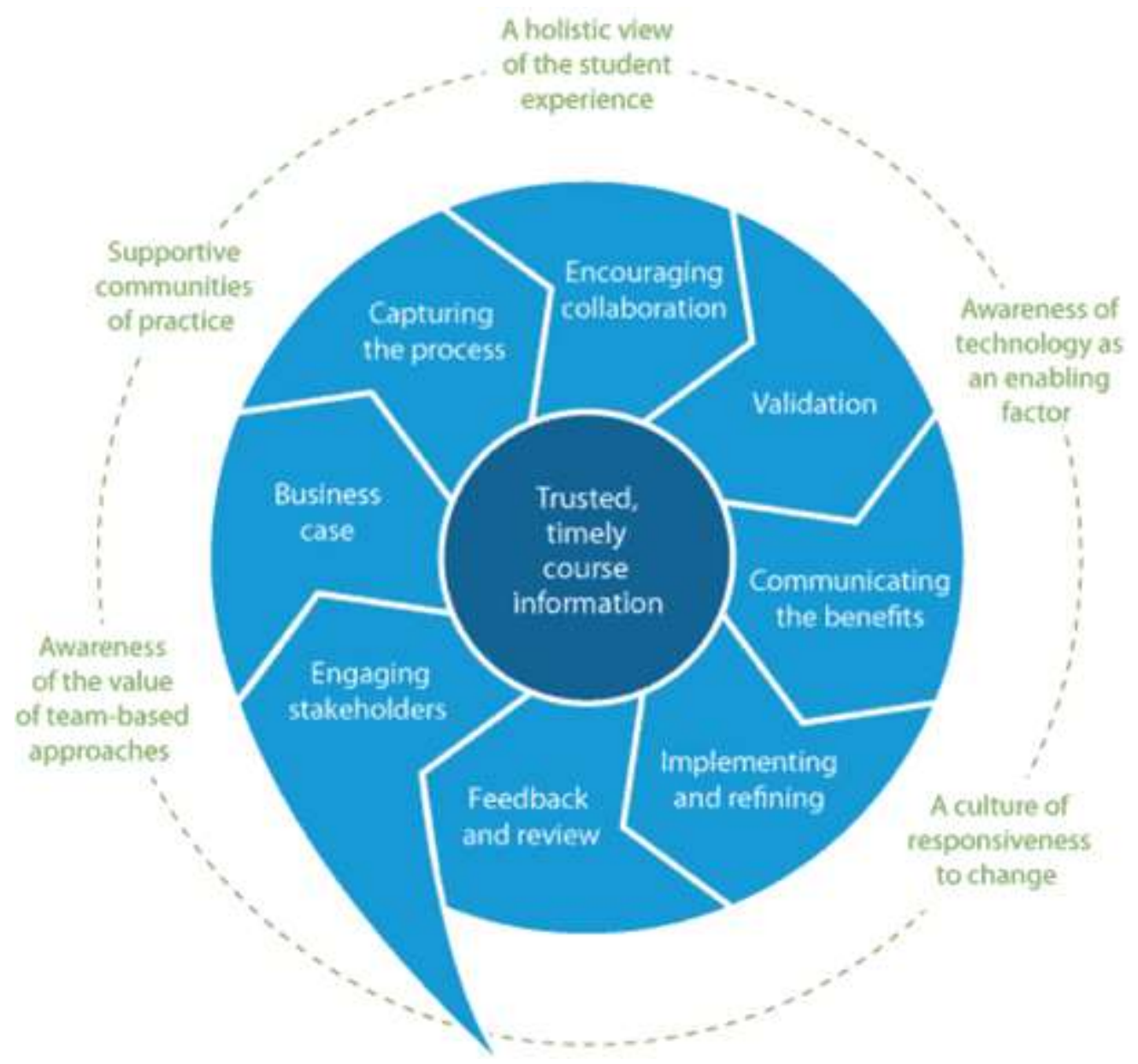

The aforementioned recent improvements in software and hardware offers a number opportunities for instructors to improve students' experience. In addition, the costs are now significantly smaller. Indeed, instructors entering the higher education sector can now find, not just useful software and advanced devices, but also helpful support, guidance and the experience of colleagues who have been pioneering new technologies and reported them in the literature.[4] 
While technology has become widely available and it clearly meets some of the requests of students, economics instructors have been historically reluctant to consider innovative forms of teaching in favour of a more traditional "chalk and talk" approach.[5] Nonetheless, in the last decade instructors have increasingly opted for a blended approach, where innovative use of technology and media has been integrated with more traditional forms of teaching.

This chapter is a guide to the most popular forms of technological innovation in higher education teaching, with a particular focus on economics. Given the continuous advance of technology and practice, the guide cannot exhaustively cover all possible forms of innovation. Rather, our objective is to offer a critical description of the most common practices currently in use. Our approach will be based on personal experience and indirect experience of other instructors and students, as reported in a growing body of literature. We shall point out where the technologies' features align with students' preferences. We shall also point out possible issues, pitfalls and problems associated with some of the technologies considered. What we hope will be clear is that innovative uses of technology are important for any instructor to consider. They are sometimes a necessity; indeed, due to the large number of students attending introductory modules, online material (for example slides, video clips, online practice and assessment) often provides a coherent and consistent substitute to personal interaction.

The use of media and, in general, technology can also help freeing valuable time during lectures that can be used in more effective ways. We shall stress the advantage of asking students to contribute in producing digital material (this is case with social media, but also videos/photos). Digital, online accessible, interactive material would also prove very helpful for those students affected by disabilities. All in all, the use of media can improve students' engagement and improve their learning experience.[6]

A caveat to keep in mind is that innovation often comes at a cost. This is true for instructors, who need to learn how best to apply a new tool; for students, who need to learn appropriate use of the technology and for the institutions that will be asked to pay for the innovation. The increased availability of technology inside and outside the classroom decreases these costs, but they are significant nonetheless and the pedagogical advantages should always be compared to the potential costs (see Stephenson and Cortinhas (2013)). Innovation for the sake of it would not improve students' learning experience.

Each section of this chapter focuses on a particular type of technological application. In Section $\underline{2}$ we discuss the use of lecture recording. In $\underline{\text { Section } 3}$ we discuss the use of media files (for example visuals, audio files, video clips, online media) embedded in classes. In Section 4 we describe the use of personal response systems (sometimes called clickers) that allow students to answer multiple choice questions interactively and anonymously during lectures. In Section 5 we describe the use of mathematical software to produce dynamic images and to create adaptive online assessment. Finally, in Section 6 we consider the use of social media to communicate and interact with students. We shall discuss how each technology can be used to improve students' learning (for example, digital media can provide examples and applications), provide learning support to students (for example via the use of recorded lectures and social media), entertain and engage students (see Mann and Robinson (2009)), provide practice and revision opportunities (for example using clickers during lectures or recent platforms for online assessment). 
[1] https://www.jisc.ac.uk/news/digital-savvy-students-offered-5k-grants-20-may-2013

[2] https://www.jisc.ac.uk/guides/what-students-really-want

[3] https://www.jisc.ac.uk/guides/using-technology-to-improve-curriculum-design

[4] See for example https:/www.jisc.ac.uk/guides/online-learning

[5] See, for example, Watts and Schaur (2011) and Goffe and Kauper (2014).

[6] See Manochehr (2006), Olczak (2014), Raymond et al. (2008).

\section{Lecture recording}

Lecture recording allows instructors to capture lectures as a media file that is then released online to students. The technology varies. Sometimes the system films the instructor and their presentation. The advantage of this is that it records a very realistic lecture experience.[1] On the other hand, the disadvantage is that the instructor is kept close to the podium and this may result in less engagement with the students in the room. Nevertheless, the technology continues to advance, for instance using cameras that follow the instructor's movements in the room.

Other systems, instead, capture only the slides of the presentation given in the lecture, together with the audio recorded using a microphone. While these recordings may tend to feel less personal and interactive, they may give the instructor more flexibility (a wireless microphone also gives more freedom of movement) and induce a more natural teaching experience since instructors do not need to worry about how they look on camera. 
Figure 2: list of lecture recordings available for the Business Economics II students at the University of Manchester

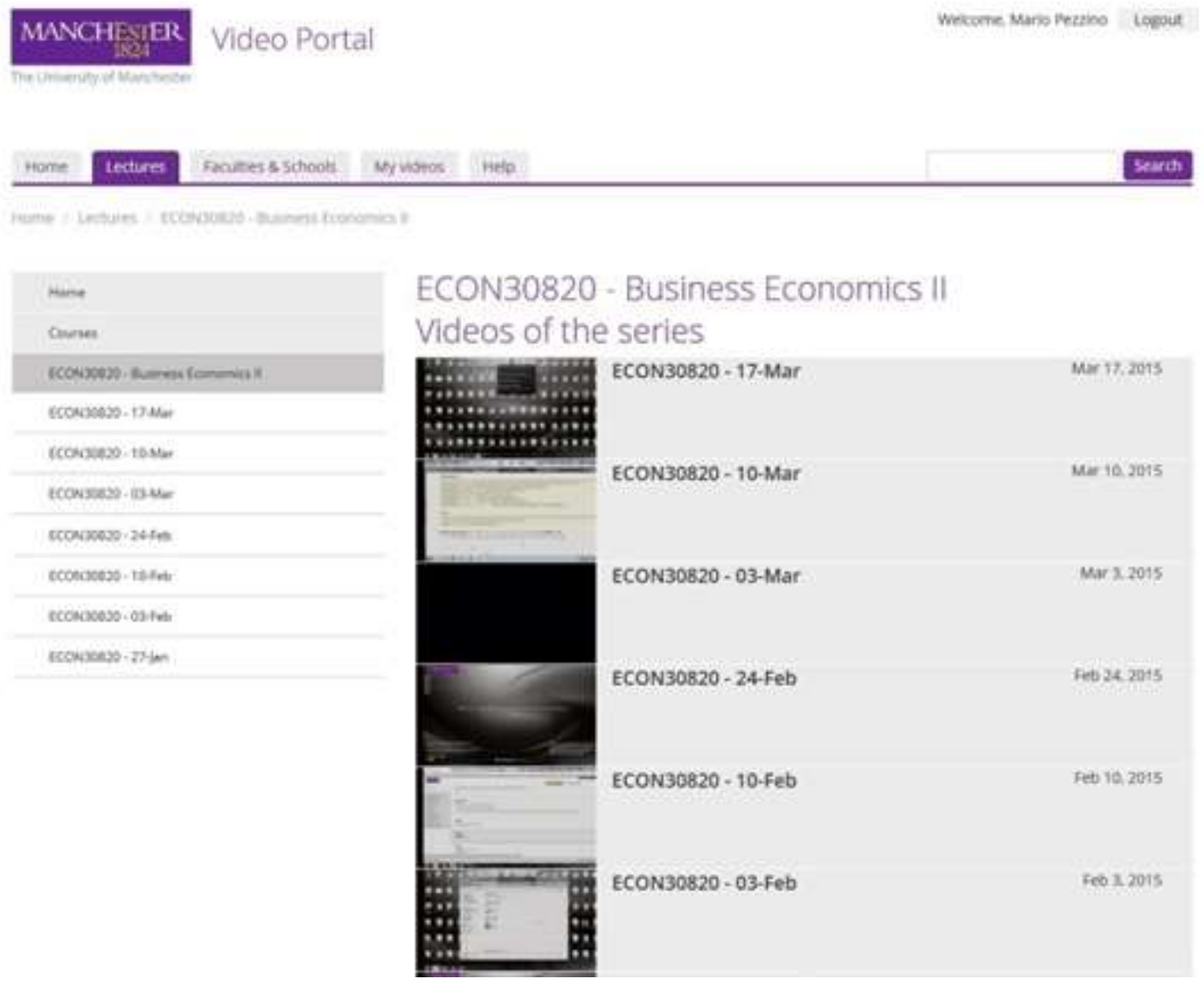

Lecture recordings offer numerous potential advantages. Recordings may provide useful support to those students who have missed a lecture. Also, since videos can be paused, rewound and fastforwarded, students can revise multiple times particularly challenging aspects of the material covered during lectures. Indeed, recordings can be useful for revision in general before an important piece of assessment.

In what follows we consider two questions. First, we discuss whether students value, and indeed use, recordings. Second, we discuss whether instructors value the use of recordings.

\section{Do students use and value recordings?}

In practice, there are important questions that each instructor should consider when releasing a lecture recording. For example, do students use recordings? When and how? What is students' willingness to pay for recordings? What are the effects that these media have on students' performance? These issues have been explored in the literature.

Agarwal and Day (1998) showed that various forms of internet enhancement to teaching (email, discussion boards, etc.) may have a positive effect on students' performance. Flores and Savage (2007) and Savage (2009) studied economics students' demand for recordings and the effect of recorded lectures on their performance. Specifically, Flores and Savage (2007) considered a type 
of recording that films the instructor and requires them to stay close to a podium. The authors used choice experiment data to estimate economics students' willingness to pay for recorded lecturers compared to instructor movement away from the podium. The analysis showed that groups of students have different willingness to pay for recordings. In particular, those who appreciate recordings were willing to pay an additional $\$ 90$. The authors, in addition, found a positive correlation between the use of recordings and exam grades.

Savage (2009) studied the effects of the release of recordings on an intermediate microeconomics module and found a positive, but not significant, effect on students' performance. It is important to notice that Flores and Savage (2007) and Savage (2009) considered rather small sample sizes. A larger sample size was considered in Chen and Lin (2012). They studied the relationship between the use of recorded lectures and exam performance among 312 microeconomics students in Taiwan. They showed that particular groups of students are more inclined to use recordings. In particular, students who tend to skip most classes and male students are more likely to access recorded lectures. In general, most students tend to access the recordings just before exams. The authors showed also the existence of a significant and positive relationship between the use of recorded lectures and grades.

In general, when asked, students tend to report that they appreciate the opportunity to be offered lecture recordings, claiming that they are a valuable support to their learning and revision. Interestingly, students' claims reported in surveys may not correspond to the actual willingness to pay for a service. Taplin et al. (2011) estimate the willingness to pay of accounting (UG and PG) students for recordings. While students claimed to appreciate the resource, only a small number of them would actually be willing to pay for it. The authors also found out that many students in reality did not access the recordings regularly. What Taplin et al. highlight is the need for a deep understanding of students' willingness to pay and their use of recordings.

Elliott and Neal (2016) used a revealed preference approach to answer these questions. The authors monitored for two years the frequency of access to recordings, the time of day and the length of viewing for students taking a large year 1 economics module. They identified spikes in access in the days before pieces of assessment were released. They also detected regularities in the use of the lecture recordings. Interestingly, the authors reported a significantly higher use ( $84 \%$ and $95 \%$ in each respective year) of the resources than previously reported in the literature.[2] The authors argued that lecture recordings are treated by students as a supplement to lectures rather than a perfect substitute. Finally, they mentioned how lecture recordings may provide invaluable support to students with special learning needs. Indeed, instructors should not forget that such students may welcome the opportunity to pause or go multiple times over a lecture.

Jones and Olczak (2016) studied the effect of lecture recording on the cohort of a large introductory economics module taught in a Business School.[3] They showed that students' performance in other modules and previous economics experience are the key determinants of performance. Lecture recording, nonetheless, tends to help counteract the lack of previous economics experience of some students. 
Sometimes students may be asked to contribute to a lecture. In particular, they may be asked to present in front of the class. In this type of situation lecture recordings may become a powerful tool to improve students' confidence, communication and presentation skill.[4] Students would be able to watch the recording of their presentation and, accompanied by feedback from the instructor and the rest of the class, can learn and improve their communication skills.

\section{Do instructors use and value recordings?}

While evidence appears to point toward a general appreciation by students of the resource and a positive effect on their performance, instructors may sometimes be uncomfortable with lecture recording. In general, their reasons are that recordings may have a significant negative effect on students' attendance and instructors' performance may be affected by the awareness that they are being recorded. Regarding the first issue, evidence is inconclusive about whether release of recordings affects lecture attendance.[5] In addition, we would invite instructors to consider whether lecture attendance should be valued per se. In other words, is a reduction in lecture attendance necessarily a problem (especially when evidence seems to show that students' performance is nonetheless positively affected by the recordings)?

We see two considerations that need to be discussed. First, students will be inclined to attend lectures that provide some element of useful interaction. A lecture based on a one-way delivery of information would be completely captured by a recording and students would have no incentive to attend. For this reason, the use of technological innovation (some of which we shall discuss in this chapter) that allows instructors to better interact with students would prove to be an excellent ally to the instructor who values lecture attendance and interaction. Second, if the students almost exclusively learning from recordings are able to perform at least as well as those students who attend the lectures, this may imply that module assessment may need some rethinking. In particular, assessment should be tailored in a way to favour critical thinking, discussion and communication skills. In other words, if students knew that they will be assessed on their critical understanding of the subject and lectures provided a platform for critical discussion and interaction, then students would be incentivised to attend lectures and recordings would be a very useful supplement, but not a substitute, to classroom teaching.

Instructors should also try to overcome the fear that their performance may be negatively affected by the awareness that their words and teaching are being recorded. Indeed, even if institutional lecture recording were not in place, nowadays students possess portable technology to record lectures. It is a fact that our teaching is already being recorded, even without our knowledge or consent. It would be, then, advisable if instructors embraced the fact and used the recordings as an opportunity to improve their delivery.

A final note on lecture recording. There may be some legal considerations that should be taken into account, especially when students present during lectures.[6] We advise instructors to seek advice from their institution's eLearning support.

[1] See Flores and Savage (2007). 
[2] See also Andrews et al. (2013).

[3] See also Davis et al. (2009), Al Nashash and Gunn (2013) and Woo et al. (2008) for similar contributions in engineering departments.

[4] See Smith and Sodano (2011).

[5] See Toppin (2011).

[6] https://www.jisc.ac.uk/guides/recording-lectures-legal-considerations

\section{Digital media}

Nowadays, technology allows instructors to produce more effective and engaging digital media at ever lower cost. Instructors may decide to release digital media for various reasons. Ultimately, media can help students with understanding difficult concepts, they engage their attention and entertain, and, if used in a flipped classroom, free valuable lecture time for discussion and interaction.

\section{Digital media and flipped classrooms}

In a flipped classroom (see Lage et al. (2000), Yamarik (2007), Bishop and Verleger (2013) and Roach (2014)), students are expected to watch videos (or any other type of digital resource) before coming to class, replacing time that would be spent in a conventional lecture. Specifically, video can convey essential information that may be a prerequisite to a specific lecture, including dry and technical material such as the proof of a theorem, solutions to long exercises, etc. Particularly abstract or complicated concepts may be best conveyed using visual support (see for example Vazquez and Chiang (2014)) such as video and dynamic plots produced using mathematical software. This would free time during contact hours to test students' understanding and to discuss more advanced and engaging material, including real life examples and applications.

Before providing a critical description of types of media that can be used, we offer a general caveat. It is important to make sure that students understand when and why they are expected to access particular media. They have to know what they are required to do and what role the media play toward their learning. In other words, instructors need to make sure that media that are deemed essential for the learning of students are clearly indicated (for example with the description accompanying the link on the learning environment). In addition, students need to be told when and why they are expected to access the media. Flooding lectures and virtual learning environments with digital media without providing guidance would be confusing and counterproductive.

Figure 3: example of media available in the virtual learning environment Blackboard 


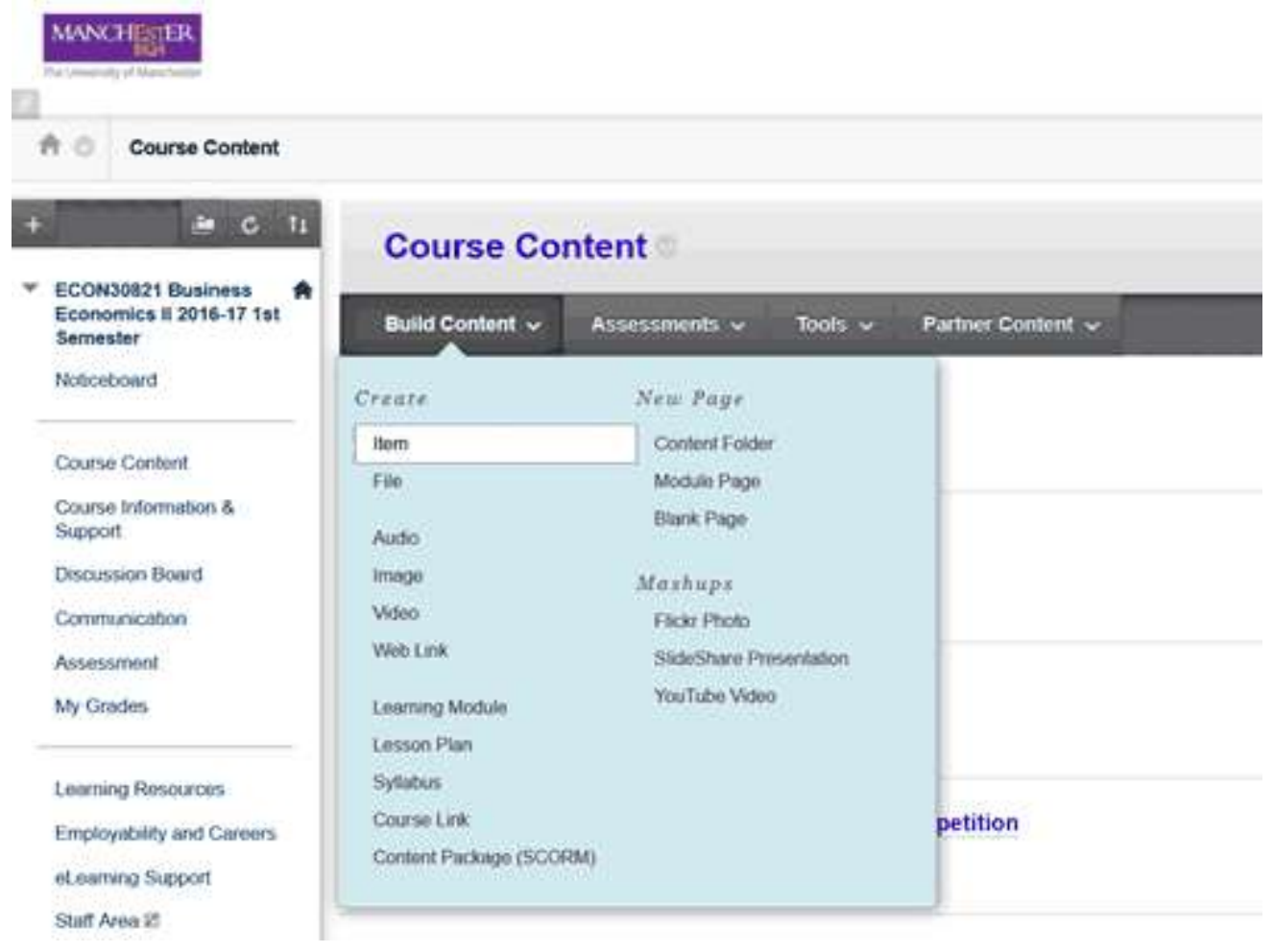

In what follows we discuss the advantages and disadvantages of various types of digital media that could be produced and released to students.

\section{Audio files}

The advantage of audio files (for example MP3) is that they are easy and cheap to create and they can be easily accessed by students.[1] For example, standard mobile phones would allow instructors to create audio files and students to play them in environments where other forms are learning are not feasible, such as while running or at the gym). Audio files can provide an introductory description of a lecture or a topic, or personalised feedback on the work submitted by students[2]. It is important to keep in mind the possibility that students with hearing disabilities may be part of the cohort. In this case, instructors should make sure to provide the same information contained in the audio files using a visual medium. Disability support colleagues can advise on alternatives.

\section{Visual material}

Learning via visual experience tends to be effective and long-lasting.[3] Visual media can provide accessible, immediate and sometimes interactive information. Photos, diagrams, graphs can be easily created[4], outsourced[5] and shared with students, whether as part of a lecture presentation or linked in their own right. To be most effective, visual media should be effectively labelled and properly integrated in the presentation (for example adequately introduced and accompanied by text/audio description). 
Pictures with humorous content, sensitively chosen, can entertain and engage in an otherwise long and technical section of a lecture.

Figure 4: a humorous description of elementary functions according to the "maths dance"

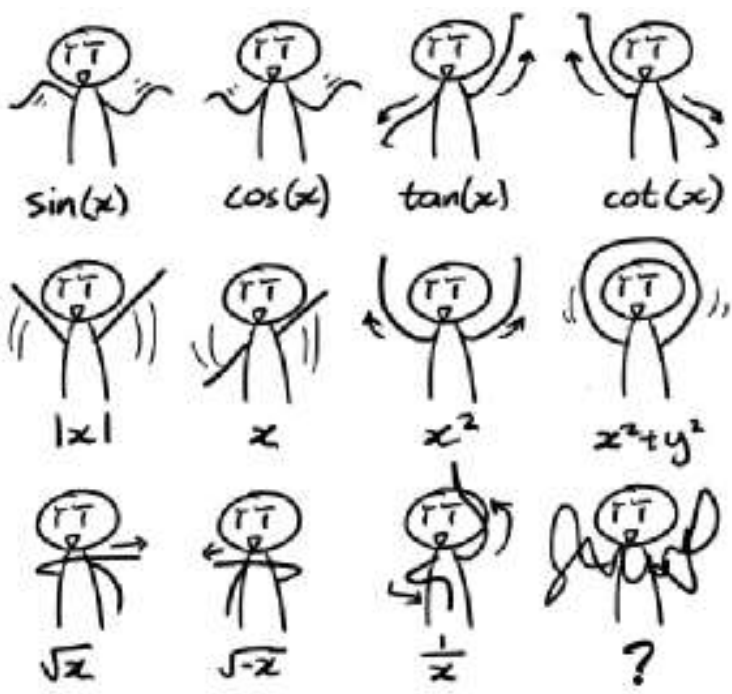

\section{Videos}

As well as images and audio files, economics-related videos are increasingly available online to instructors and students. Online videos on statistics and mathematics are provided via, respectively, the DeSTRESS[6] and Metal[7] projects. Videos from public sources (for example YouTube) can be embedded in virtual learning environments and support the other course material, by illustrating an aspect of it or by providing an alternative mode of explanation.

Figure 5: examples of Youtube videos uploaded on Blackboard for the Advanced Mathematics students at the University of Manchester.

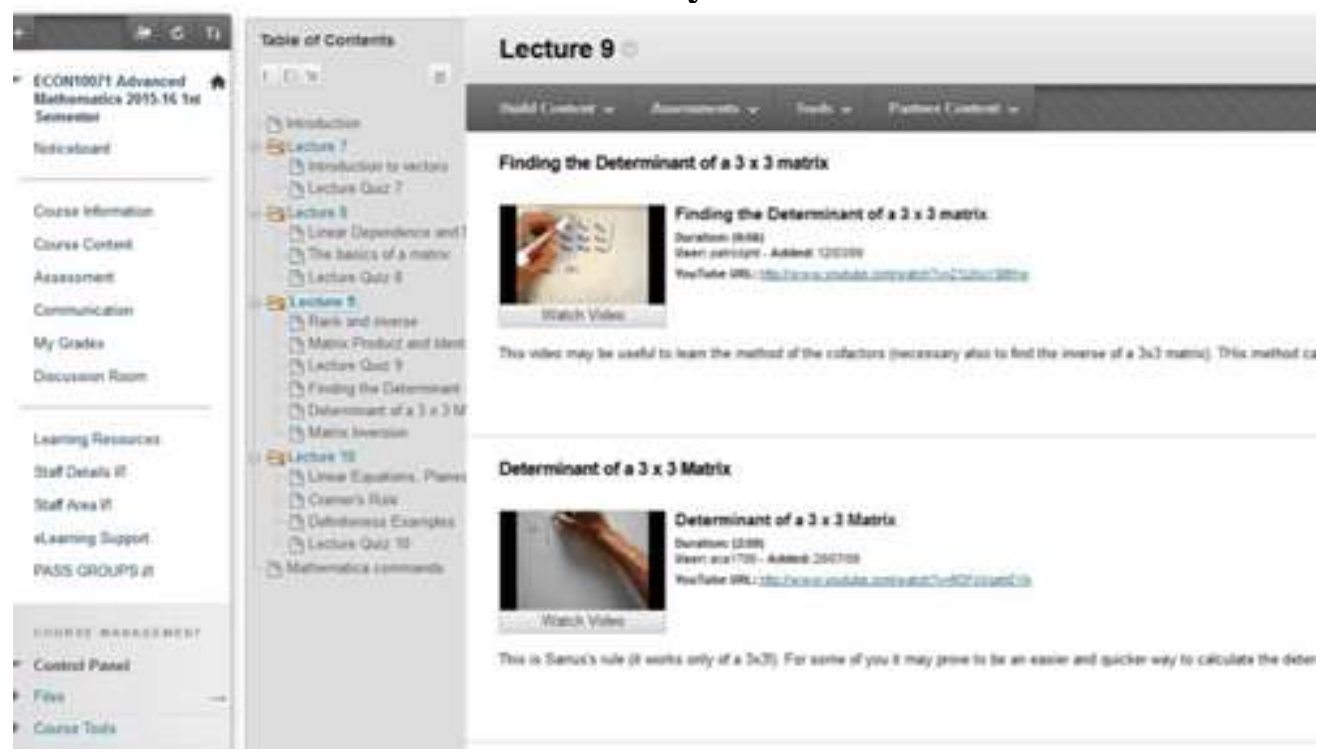


In addition, videos can stimulate discussion, if played in suitably equipped lecture rooms. It is advisable that, before playing a video during lectures, instructors provide some preliminary information to students, for example asking them to consider specific issues that will be then discussed after the end of the video.

It is well-known that the attention span of individuals is significantly less than the one hour of a standard lecture. A video can break up the monotony and re-engage students.

\section{Economics in popular culture}

There is an increasing number of sources providing videos that convey economics concepts via the medium of popular culture. For example, Dirk Mateer's site provides a large number of economics-related videos making use of pop culture examples. A list of "distractions" (including films, video clips and songs) for economics students and instructor is also available on the StudyingEconomics.ac.uk site. There are also sites that present economics concepts using clips from popular TV series. See, for example, The Economics of Seinfeld, Economics of "The Office" or, more recently, Bazinganomics which provides clips from the popular show "The Big Bang Theory" where economics/mathematics concepts are mentioned or hinted at.

Figure 6: the homepage of Bazinganomics.

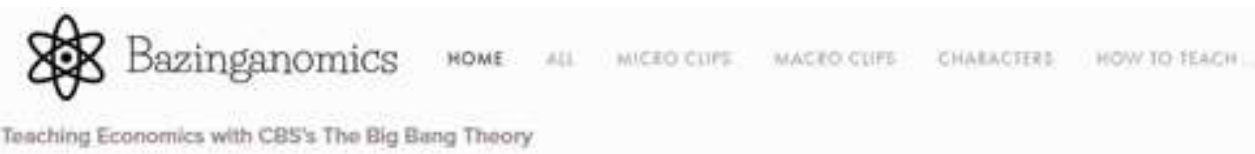

Teaching Economics with CBS's The Big Bang Theory

$$
\text { Q Seavin }
$$

Welcome to Bazinganomics!

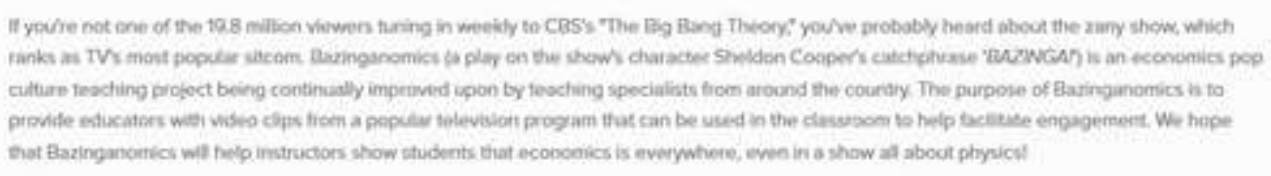

FEATURCD

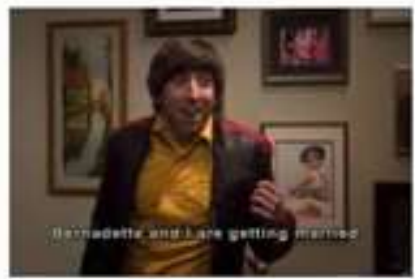

WHAT CAUSED THE HEART ATTACK?

Howitch mon pesses out itere kewnino about Howed ana bernachttes engageenit.

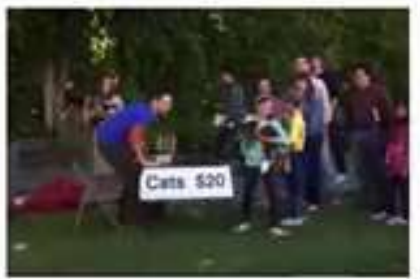

CATS: AN ECONOMIC BAD sholdoo mut per 520 wo pet peckin to tate in cass.

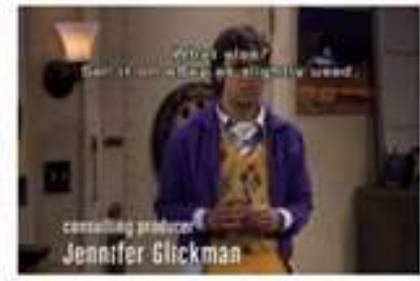

A SLIGHTLY-USED IPOD

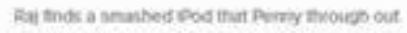

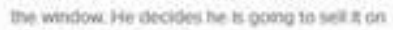
nelay as stominy vied: 
With these and similar sources, there is a potential to find a clip that lightens the tone and reengages students (if that is needed) while still connecting to the content of the lecture.

\section{Homemade videos}

Instructors do not need necessarily to outsource videos. Advancements in hardware (for example the increasing affordability of tablets provided with a stylus pen) and software[8] allow instructors to create their own videos, populate their own YouTube channels and, ultimately, provide material that students can access online or download. For example, preliminary introductions to a topic, proofs of theorems, or solutions to exercises can be all captured in a video for students to watch before the lecture. As well as providing helpful support to students that complements the lecture, videos also free up contact time for interaction and discussion of more advanced and engaging material, including real-world applications. 
Figure 7: Videos on oligopoly theory, created with Camtasia software, available in Blackboard to Business Economics II students at the University of Manchester.

MWNCH:SIER

Af Course Content Topic 1-Oligopely Theory , VIDEO CuPS

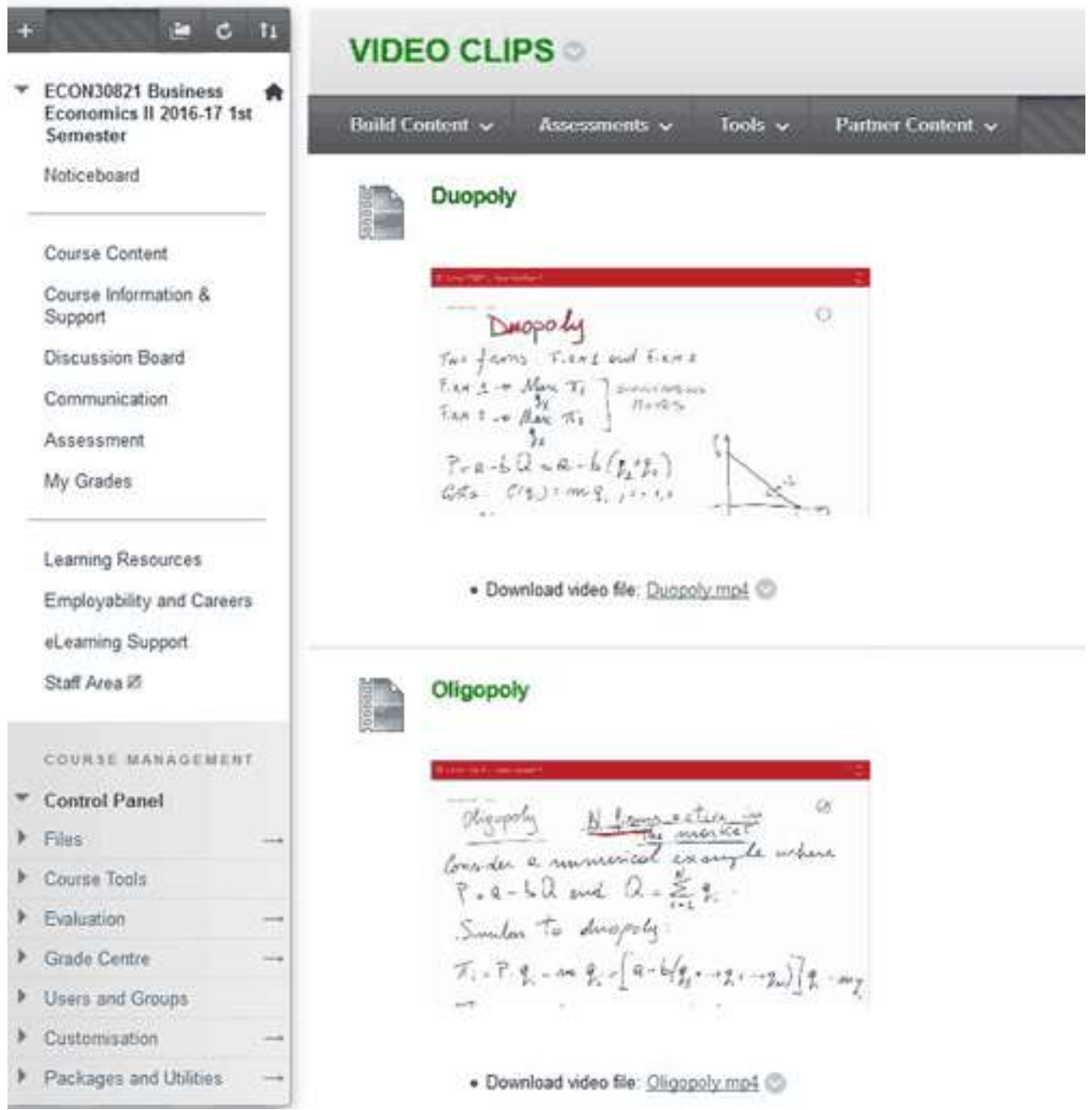

With modern smartphones and tablet devices having quite sophisticated cameras and editing software, students are in a position to produce their own audio and video material. Instructors should consider challenging student groups to create their own material applying economic concepts.[9] This involves students in collaboration, subject knowledge and information skills as well as employable communication skills. We shall discuss student-made media in some detail in Section 6.

Figure 8: Recording and editing a video clip with Camtasia software 


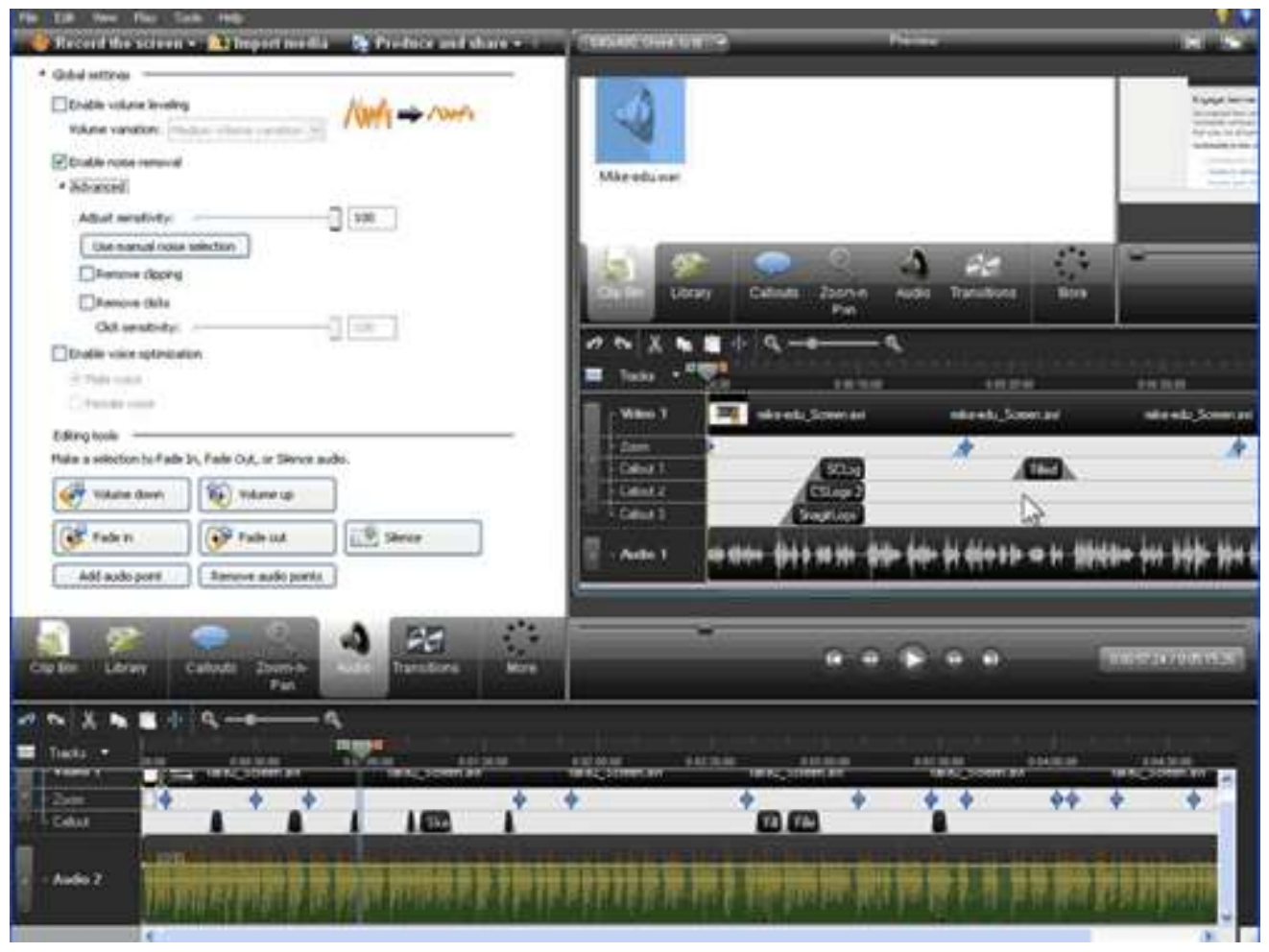

Figure 9: a flash video embedded in lecture slides for Advanced Maths students at the University of Manchester.

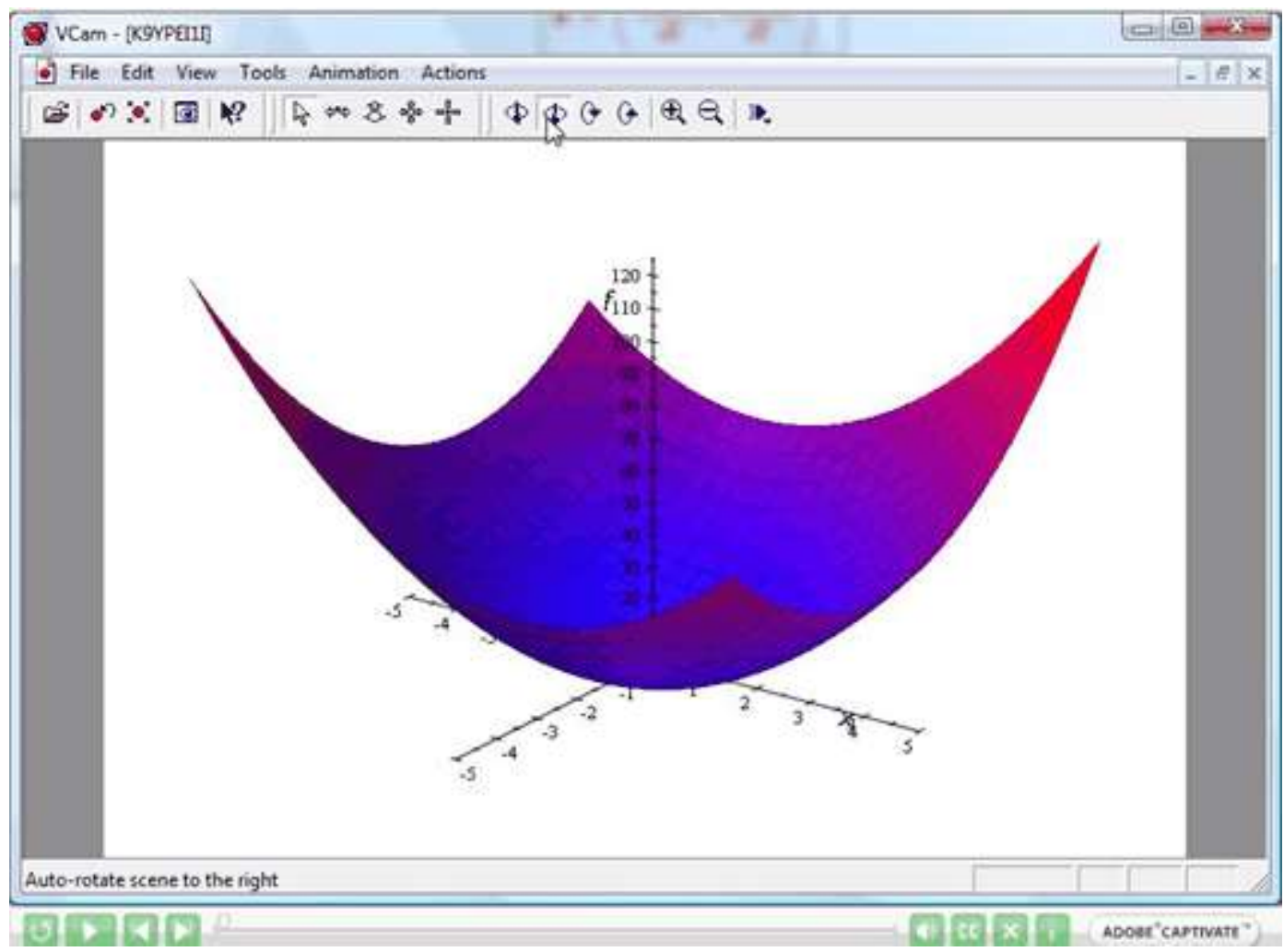


[1] Text-to-speech tools help instructors to turn digital text into audio files. Text-to-speech tools can be found in Microsoft Office and Acrobat Reader and plugins are available in popular internet browsers such as Google Chrome and Mozilla Firefox.

[2] Online assessment tools, such as TurnitIn (see Stephenson and Cortinhas (2013)) and the assignment tool in the virtual learning environment Blackboard allows instructors to record audio feedback for students.

[3] This pedagogical approach has been adopted by the Montessori method of teaching mathematics to primary school children. Interestingly, algebraic and geometric concepts and procedures (for example how to calculate the cube of a binomial) can be easily and effectively be taught to students using visual objects like the Montessori binomial cube. See also Vazquez and Chiang (2014).

[4] Graphs and diagrams can be created with the Microsoft Office package (or similar open source alternatives). More advanced (for example 3D plots) can be created with mathematical software such as Mathematica or Maple. Pezzino (2016) discusses the use of dynamic plots created with the software Mathematica to teach economics concepts such strategic interaction in oligopoly models.

[5] Alternatively, copyright-cleared images are easy to source from a range of collections including Pixabay, Flickr CC and Wikimedia Commons.

[6] http://www.economicsnetwork.ac.uk/statistics

\section{[7] http://www.metalproject.co.uk/}

[8] Screencast-o-matic, TinyTake or Jing are examples of screen capture software that allows instructors to add audio (such as music or their voice) to the capture of their computer screen and produce video files. Latest versions of Microsoft PowerPoint have a screen recording tool under the Insert options. Features such as video editing and online sharing in Youtube channels are also provided in applications such as $\underline{\text { Camtasia. }}$

[9] Getting students to produce audio/visual material to be used and reviewed by their peers is in the same spirit as using wikis to create text-based material (see Stephenson and Cortinhas $\underline{(2013))}$.

\section{Personal response systems ("clickers")}

We have mentioned above the importance for students of interaction during lectures. Interaction is essential to engage and motivate students and, ultimately, to incentivize them to attend classes, especially if lecture recordings are available online.[1] Of course, interaction is not always easy, especially in larger classes. One way to interact with the class involves posing (multiple/discrete choice) questions which students answer by raising their hands or, for more variety of response, 
coloured cards. While commendable, this approach has at least two drawbacks. First, students' answers are not anonymous and this may affect responses. Second, it is not always easy to extract and record information from a sea of raised hands.

Fortunately, technological advancements include personal response systems that anonymously collect and record the answers of students. A popular system is TurningPoint.[2] Specifically, instructors can embed MCQs in Microsoft PowerPoint presentations which students answer using remote controls ("clickers") that have been distributed at the beginning of the lecture. These are wirelessly connected to a USB dongle on the lecture theatre PC. The advantages of clickers have been reported by various contributions in the literature. Laurillard (2013) discusses the role that questions, rather than answers, may play in encouraging understanding. Draper and Brown (2004) and Bruff (2009) stress the benefits to students' learning of giving them a more active role.

Figure 10: the PowerPoint command panel enhanced with TurningPoint features.

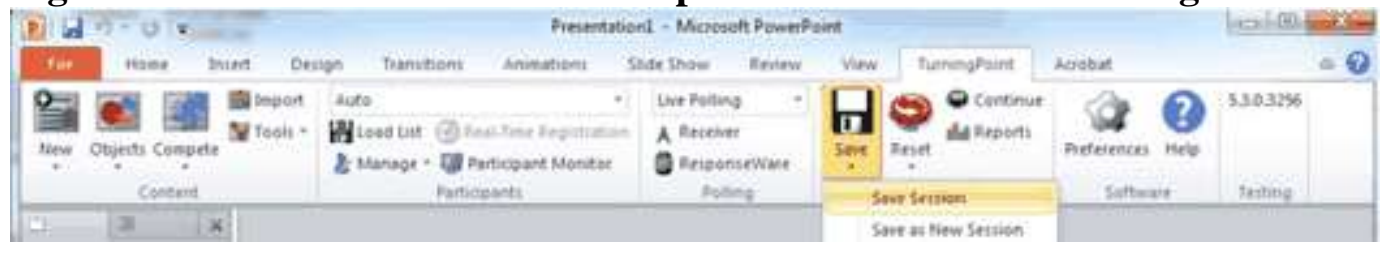

The software records the answers and produces reports that can be shown and discussed with the class. 
Figure 11: the new QT2 handset (on the left) and a smart phone (on the right) showing the result of a poll.

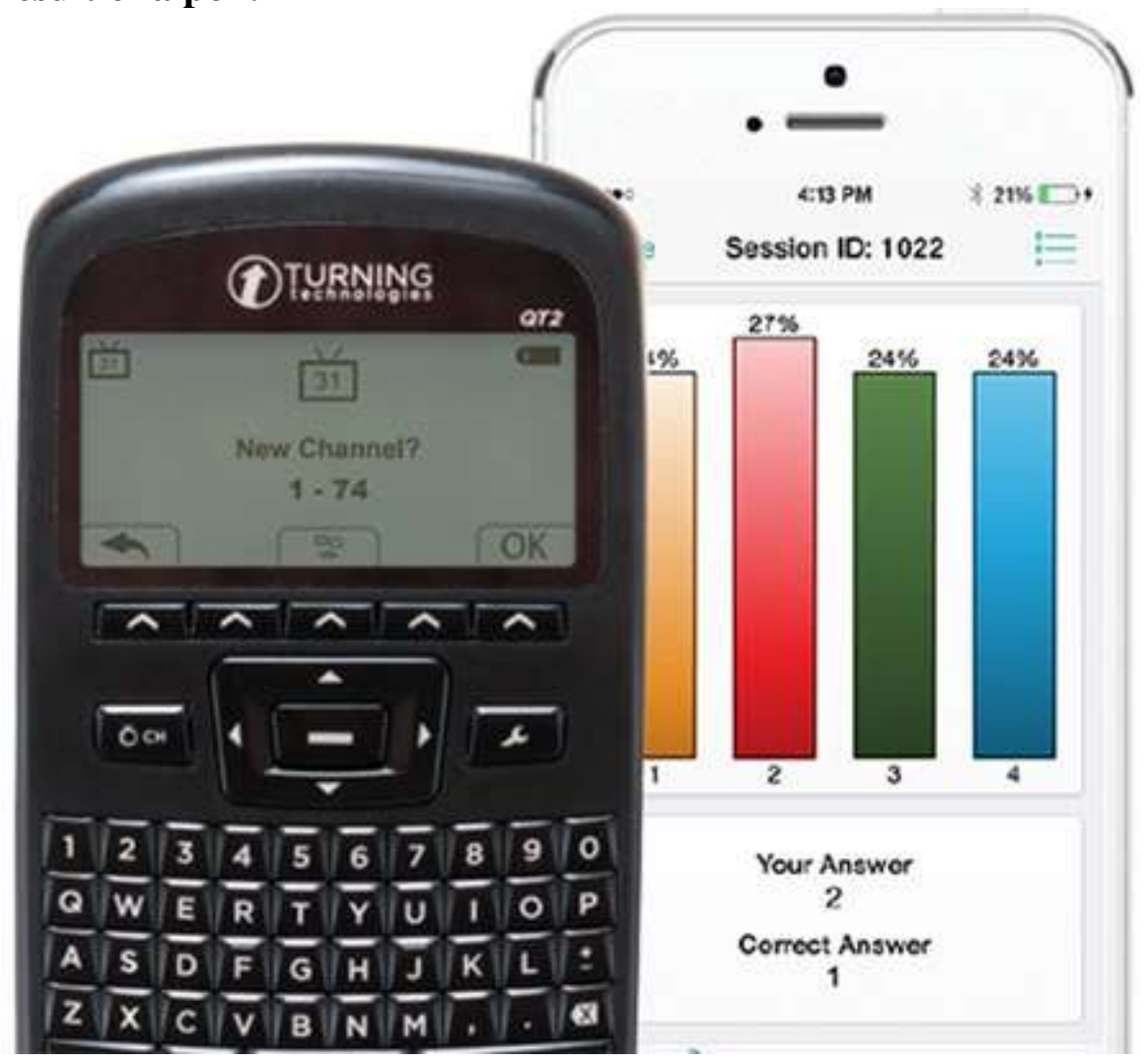

Personal response systems are particularly useful when teaching large classes. Carrying, distributing and collecting a large number of (expensive) clickers may be, however, a little discouraging for many. Recently it has been noted (see Middleditch and Moindrot (2015b)) that an increasing number of students have portable devices (smartphones, tablets and laptops) with internet access during lectures. Recent software developments[3] take advantage of students' own hardware and make the use of clickers unnecessary. Essentially, students are given a web link through which they can provide answers online. 
Figure 12: TurningPoint/Responseware on multiple devices.

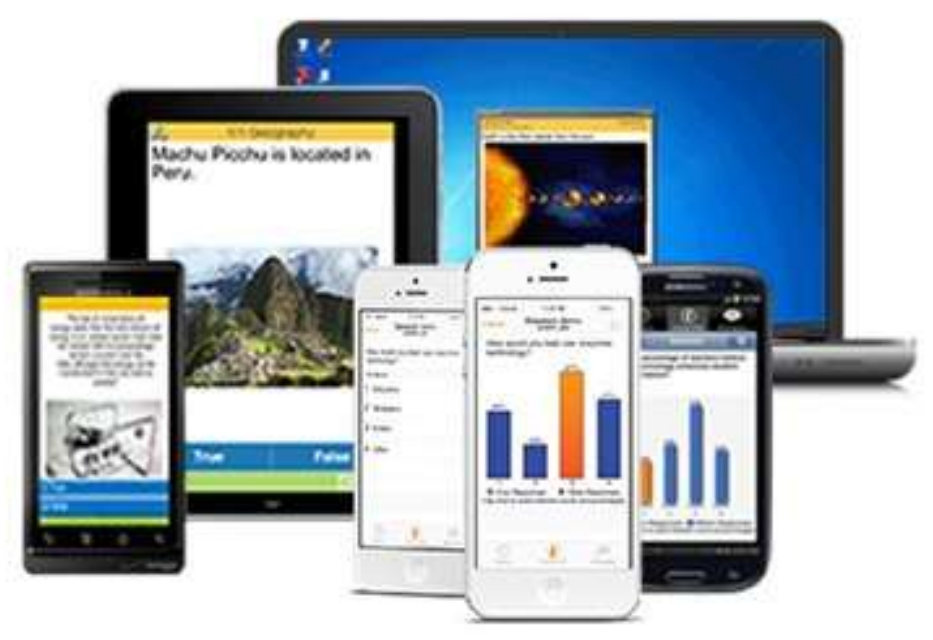

Personal response systems can enhance a lecture in a variety of ways.[4] Of course, questions are ideal to make the lecture more engaging and interactive.[5] Instructors can ask a question at the beginning to introduce a topic, store the answers provided by students, and then ask the question again at the end of the class to see changes in students' understanding. Questions can be released at the end of a lecture or topic to recap or test students' understanding. Thanks to their anonymity, and new systems that allow free-text input, personal response systems can also collect more varied information from students, including feedback on the lecture.

\section{Peer Instruction}

A very interesting way to employ a personal response system is peer instruction (see Crouch and Mazur (2001)). Peer instruction uses structured questioning and small group discussion tasks. This approach has the potential to engage students through discussion. Employing peer instruction, Middleditch and Moindrot (2015b) discuss how personal response systems can facilitate interaction among students during a lecture. Students may be asked to discuss and motivate their answers with peers. The instructors then reiterate the questions and discuss with the class any change in the distribution of answers.

If carefully planned and adequately managed,[6] personal response systems allow instructors to engage students while providing them with useful information, practice and interaction. Wellchosen questions can enhance the lecture material, giving students another level of involvement and giving the lecturer useful feedback. In section 6 we shall discuss how instructors can also use social media to interact with students.

Student surveys report a positive evaluation of the use of clickers. Elliott (2003), in particular, describes a very positive experience related to the use of clickers in an intermediate microeconomics module. Similarly, Middleditch and Moindrot (2015a) point out an increasing use of student-owned devices to access the personal response system and a consistent positive effect in student satisfaction in (year 1 and year 2) macroeconomics modules. 


\section{[1] See Simpson and Oliver (2007).}

\section{[2] https://www.turningtechnologies.com}

[3] There are various platforms in the market that provide solutions that allow students to submit answers using their smartphones/tablets. Among others, instructors can consider Responseware, $\underline{\text { Socrative and PollEverywhere. }}$

[4] For a collection of case studies see: https://www.turningtechnologies.com/case-studies

[5] See Broussard (2012), Freeman et al. (2007) and Koenig (2010).

[6] Draper and Brown (2004) suggest that spending time carefully developing effective questions is essential to maximise the benefits of a personal response system.

\section{Online assessment and the use of media}

Online assessment is very common in economics modules. Its key advantage, especially for large classes, is immediate feedback to the students. Moreover, online practice with objective-answer questions, can be very useful for students to reinforce their understanding and can be used by instructors as formative and summative assessment. Indeed, many textbooks provide companion websites that supply supplementary material including assessment based on multiple choice quizzes.[1]

Popular learning environments provided by publishers include Pearson's MyEconLab (and new arrival Revel), McGraw Hill's Connect, Cengage's Aplia and Wiley's Wiley Plus. Virtual learning environments, such as Blackboard and Moodle, allow instructors to construct assignments from multiple choice, true/false, fill-the-blanks, and other types of questions. In addition, questions can embed figures, diagrams and audio or video clips.

Standard online assignments have drawbacks, however. Questions and feedback tend to be standardized. Especially with MCQs, students are not incentivised to understand the material in its entirety, but only have to identify (often by a process of sequential elimination) the answer most likely to be correct.

There are two recent developments that could allow instructors to move away from standard and repetitive MCQs. The first is the use of more interactive visual material, such as clickable images and interactive diagrams. The second is the possibility for questions to adapt to students' performance; for example, questions that, if answered incorrectly, provide additional questions and hints to help the student towards a correct answer. The platform MapleTA,[2] built around the mathematical software Maple, supports the creation of algorithmic questions and analytic manipulation.[3] It can also create adaptive questions and clickable diagrams. A very important advantage of MapleTA is full integration with virtual learning environments such as Blackboard. This means that taking an assignment does not require logging in to a different site. 


\section{Clickable images / Sketch-the-graph questions}

MapleTA allows instructors to create questions that show a visual item (for example a diagram, a figure, even a table with data) where students are asked to identify a particular portion and click on it. Figure 13 shows a question asking students to identify the area of the graph representing the profit of a monopolist. The advantage of this type of question is that students interact directly with the figure, instead of picking the most likely alternative among a set of possible answers.

\section{Figure 13: example of clickable question in MapleTA}

e Unveraty of Manchester - Frevien - Mosils Findox

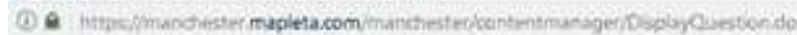

\section{Maple T.A.}

\section{Preview}

Clickable Profits Monopoly

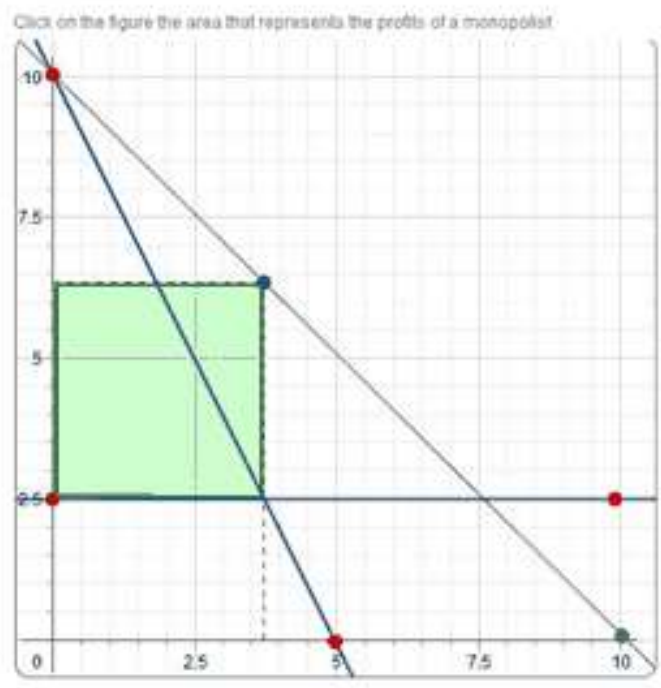

\section{Gade How did I do? Corse}

The visual content does not have to be a diagram. Figure 14 below shows a question asking students to study the payoff matrix of a very simple $2 \times 2$ simultaneous move game and identify a player's best response. Again, students will have to understand and interact with the whole payoff matrix, not just a subset as is often the case with MCQs. 
Figure 14: clickable image question with a pay-off matrix

Maple T.A.

\section{Preview}

Game1

Player 1 and Player 2 play a simutaneous move gane and pay-otts are represented in the tablo beicw. Suppose that Player 1 chooses $\mathrm{Mr}$

What is the best response of Player 27 click on the correct cell.

Player 2

\begin{tabular}{cc|c|c|c} 
& & $\mathrm{L}$ & $\mathrm{M}$ & $\mathrm{R}$ \\
\hline \multirow{3}{*}{ Player 1 } & $\mathrm{T}$ & $(100,75)$ & $(120,70)$ & $(140,60)$ \\
\cline { 2 - 5 } & $\mathrm{M}$ & $(95,90)$ & $(130,95)$ & $(150,100)$ \\
\hline & $\mathrm{B}$ & $(90,110)$ & $(120,120)$ & $(160,110)$
\end{tabular}

\section{Grade How did I do? Close}

Ideally, instructors may want students to be able to reproduce diagrams. The sketch-the-graph question type requires students to use MapleTA's graphic toolbox to draw a diagram. Figure 15 shows a question asking students to draw the demand function and profit maximisation choice from figure 13. 
Figure 15: an example of "sketch the graph" question in MapleTA

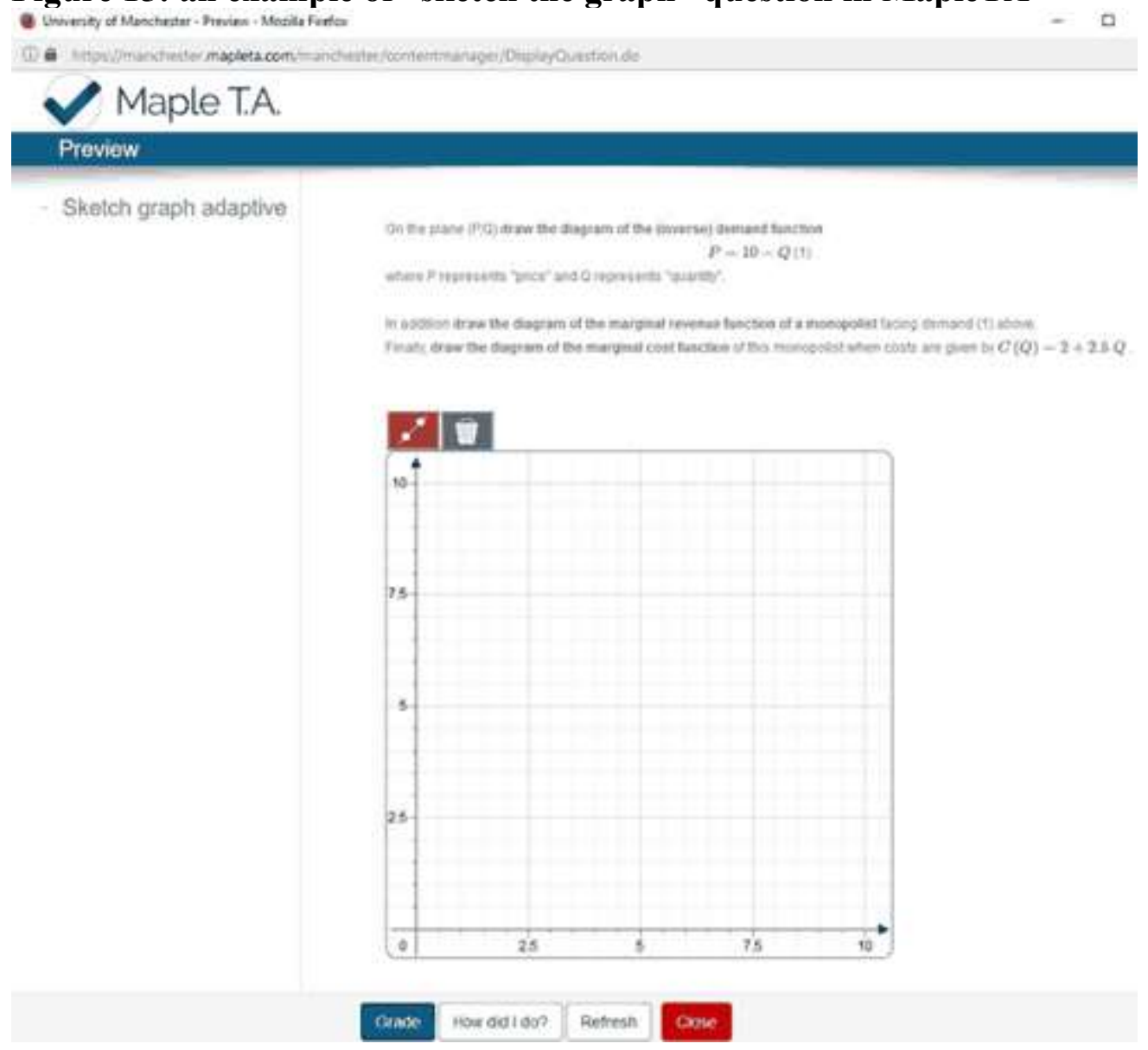

\section{Adaptive questions}

In a standard multiple choice question, a wrong answer gets no mark (or negative marks) and, possibly, feedback including the correct answer. This may be a little frustrating and disheartening to some students, in particular to those who have a general understanding of the material. Ideally, instructors would give students a combination of encouragement ("You did not get it right. It's OK, let's approach the question step-by-step"), technical information (for example "recall the concept of...") and questions (not necessarily multiple choice) to test their effective understanding. The student would thus learn to identify important concepts and apply them correctly. Eventually, the student should be awarded at least a partial mark. This is what any instructor would do in one-to-one or small group teaching.

This personalised approach cannot be replicated with standard online assignments. Fortunately, MapleTA allows adaptive online questions that do precisely what we are suggesting. Students can be prompted with an additional, and related, sub-question if they get the main question wrong. This way, instructors can guide students step by step and support them in finding alternative ways to answer the original question. If carefully designed, essentially every question in MapleTA can be adaptive and combine various question types. 
Figure 16 shows an adaptive version of the graphical question from Figure 15 above. 


\section{Figure 16: adaptive question in MapleTA}

On the plane ( $P, Q)$ draw the disgram of the (inverse) demand funetion

$$
P=10-Q(1)
$$

Where $P$ represents "price" and $Q$ represents "quantty"

In addion draw the diagram of the marginal revenue function of a monopolist facing demand (1) above.

Finaly, draw the diagram of the marginal cost function of this monopolst when costs are given by $C(Q)=2+2.5 Q$.

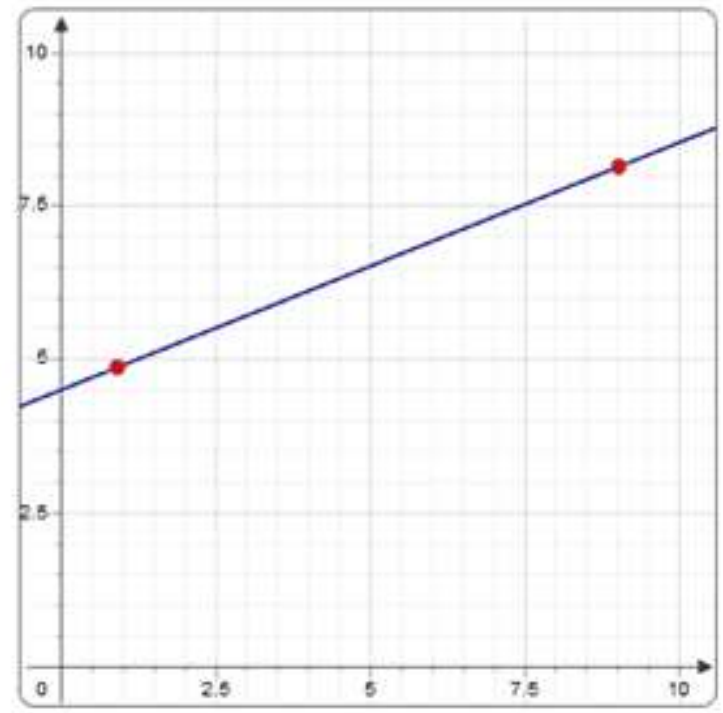

You did not get it nght No worries: Let us try step-by-step. Let us start wth the demand function

$$
P=10-Q(1)
$$

the function descrbes a linear relationshio between $P$ and $Q$.

This relationship, in particular, is negative ( $Q$ is multipled by -1 ). Notice, in addtion, that if $Q=0$, then $P=1 Q$.

in other words, we know that the demand is a lnear function, wh intercepts equal to 10 and slope equal to -1. Try to draw it now.

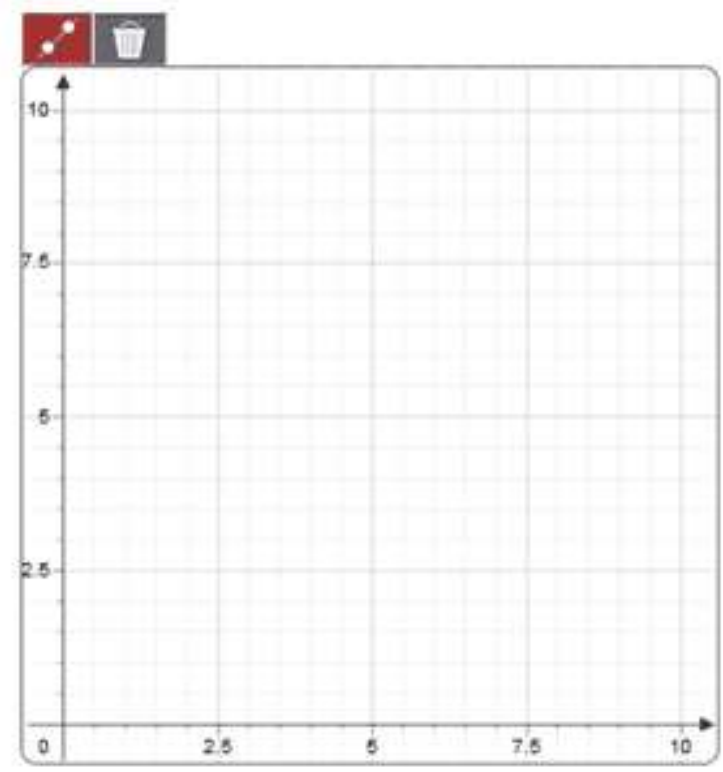


[1] Olczak (2014) identifies a positive effect of publishers' web-based resources on student learning.

\section{[2] http://www.maplesoft.com/products/mapleta/index_personas.aspx}

[3] These features should be particularly welcome by those instructors teaching modules with mathematical content. The fact that MapleTA can process algebraic expressions implies that expressions $2 a+b$ and $b+2 a$ are considered to be equal. This would not be true in assignments created within standard virtual learning environments. In addition, MapleTA allows instructors to access all Maple packages and use algorithms to create randomised mathematical objects such as variables, equations, matrices, etc.

\section{Social media and facilitating contributions from students}

Instructors are increasingly complementing their teaching resources with student input and collaboration using social media including virtual learning environments.[1] The advantage is that students can collaborate informally using their own portable devices. The advantage of social media inside and outside the classroom has been highlighted and described in Junco et al. (2011) and (2013). [2] Specifically, these contributions (using a control group) show that students exposed to social media became more engaged and performed better. The authors observed a positive effect of social media on the degree of collaboration among students. Figure 17 shows examples of tweets posted on a UG Macroeconomic Tweeter page as described in Middleditch and Moindrot (2015b).

Figure 17: the use of Twitter in a intermediate macroeconomics module as described in Middleditch and Moindrot (2015b).
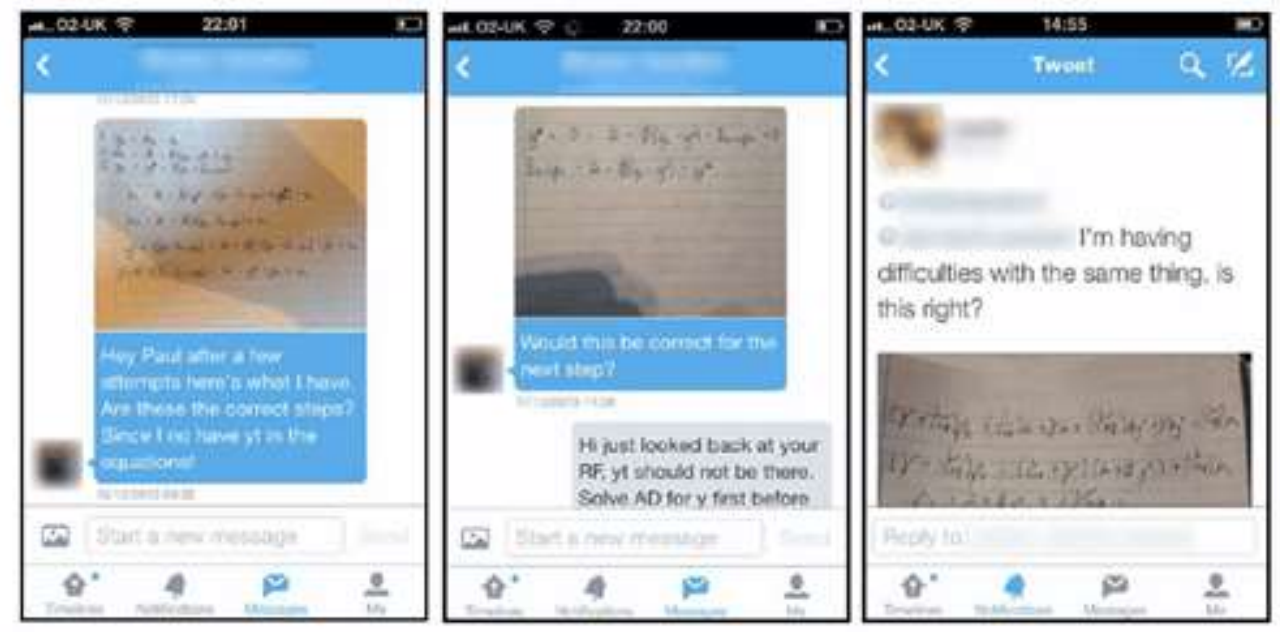

Enhanced collaboration among students is especially advantageous in a large module. Students may answer some of the questions posted by other students and contribute to the discussion. This should reduce the volume of queries to the teaching staff. 
In this respect, social media can build a role for students as creators of resources. This role offers positive effects on their understanding of the subject and their communication and transferable skills.[3] Bahrani et al. (2016), for example, describe their experience introducing "Econselfies", photos where students are asked to highlight the intuition behind an economic concept. The interesting part of the practice is to motivate students to think in economics terms using a medium - the selfie - that they are very well-versed to produce and share. In the same spirit, Spielmann and Chaudhury (2016) describe the possibility of asking students to make an "economics movie". 4] When students are assessed on the production of a media file describing an example or an application of an economics concept, they are induced to think of the concept in very real terms.

An important message here is that it does not necessarily have to be the instructor who is the producer and distributor of media content. Students can be producers as well as consumers of these media.[5] In this sense, there are various benefits available. Instructors can obtain inspiration and ideas from students' work; students can access media made by other students, who presumably may have a closer sensitivity and connection to the topic and, commenting or sharing the material can make the process of learning more collaborative.

[1] See the student guide to social media for learning, created by the university libraries of Leeds, York and Manchester available at https://www.escholar.manchester.ac.uk/learningobjects/social-media-guide/.

[2] Some contributions in the literature are, however, more cautious in attributing advantages to social media. In particular, these contributions stress Kassens-Noor (2012) and Graham (2014), the importance of carefully implementing the use of social media (including considering the use of incentives to guide students' behaviour) in a module and the possibility that social media may be a distracting force especially in those modules where student self-refection may be particularly important.

[3] See https://www.jisc.ac.uk/guides/enhancing-the-digital-student-experience/empowerstudents-to-develop-their-digital-environment.

[4] See the recent RES video competition.

[5] The same idea is behind the use of wikis, i.e. collaborative texts on economics topics created by students under the guidance and supervision of the instructor. See Stephenson and Cortinhas $\underline{(2013)}$.

\section{Conclusions}

The aim of this chapter has been to provide a guide to some of the most popular forms of technological innovation in higher education teaching, with a particular focus on economics teaching. We have stressed that students tend to have preferences over the use of technology in education and it is important that instructors take these preferences into consideration 
when innovating in their teaching. Indeed, if technological innovation is carefully planned and implemented, it can help educators meet students' needs and improve their learning experience.

\section{What students really want}

In the introduction we described the insights regarding what students really want when concerned with the use of technology in higher education provided by the submissions to a Jisc competition. How do the innovation practices described in this chapter match students' needs?

\section{Personalised learning.}

Students expressed a desire for more personalised teaching. Identifying and producing digital resources (for example audio and video files) and releasing them for students to access when required can improve the learning experience. Adopting video capture, students can access the information provided during lecture at their own pace and when most convenient. In addition, the use of online assignment (possibly enhanced with adaptive features) and personal response systems allows instructors to tailor assessment and practice and revision to the particular needs of each student.

\section{Networking}

Students expressed a need to access platforms to communicate and share information with other students. We explained that personal response systems and social media allow students to interact with the instructors and with the rest of the class. Similarly, when students are asked to access online video posted by instructors, they may be allowed to post comments and initiate a debate. We also stressed that students should be invited, when possible, to contribute to discussions and production of digital resources.

We have critically discussed some of the most common forms of technological applications in higher education. In particular we have identified the advantages and disadvantages of various practices and highlighted the importance of assessing the pedagogical benefits and costs.

An important message that this chapter has put forward is that students should be at the centre of the teaching innovation process. They are the end users of the outputs of technological innovation in learning. It is essential that instructors acquire a good understanding of students' needs and, at the same time, consider ways to allow students to contribute to the development of teaching practices and digital resources that could benefit peers and future cohorts.

\section{Author's Bio}

Mario is a lecturer in Industrial Economics at the University of Manchester. He has taught UG (Advanced Mathematics and Business Economics) and PG (Health Economics) modules. He is also serving as the Economics UG Director and Economics Pathways Lead in the BAEcon Programme at Manchester. Mario is a Fellow of the Higher Education Academy, an Associate of the Economics Network and member of the Centre of Innovation in Pedagogy (University of Manchester). 


\section{References}

Agarwal, R. and Day, A. E, (1998), "The impact of the internet on economic education”, Journal of Economic Education, 29(2), 99-110. DOI 10.1080/00220489809597943

Al-Bahrani, A., Holder, K., Moryl, R.L., Murphy, P.R. and Patel, D., (2016), "Putting yourself in the picture with an 'ECONSelfie': Using student-generated photos to enhance introductory economics courses", International Review of Economics Education, 22, 16-22.

DOI 10.1016/j.iree.2016.03.003

Al Nashash, H. and Gunn, C., (2013), "Lecture capture in engineering classes: bridging gaps and enhancing learning”, Educational Technology \& Society, 16(1), 69-78.

Andrews, C.J., Brown, R.C. and Harrison, C.K.W., (2013), "Lecture capture: early lessons learnt and experiences shared", New Directions in the Teaching of Physical Sciences, 6, 56-60.

Bishop, J. L., and Verleger, M. A., (2013), “The flipped classroom: A survey of the research" In ASEE National Conference Proceedings, Atlanta, GA.

Broussard, B., (2012), "To click or not to click: Learning to teach to the microwave generation", Nurse Education in Practice, 12(1), 3-5. DOI 10.1016/j.nepr.2011.03.013

Bruff, D., (2009), Teaching with classroom response systems: Creating active learning environments, San Francisco, CA: Jossey-Bass. ISBN 9780470288931

Chalmers, D. and McCausland, W.D.M, (2002), "Computer-assisted Assessment", in The Handbook for Economics Lecturers (chapter edited by Houston, J. and Whigham, D.), The Economics Network, 1-20.

Chen, J. and Lin, T-F., (2012), "Do Supplemental Online Recorded Lectures Help Students Learn Microeconomics?”, International Review of Economics Education, 6-15.

DOI 10.1016/S1477-3880(15)30021-9

Crouch, C. H. and Mazur, E., (2001), "Peer instruction: Ten years of experience and results", American Journal of Physics, 69, 970-977. DOI 10.1119/1.1374249

Draper, S. W. and Brown, M.I., (2004), "Increasing interactivity in lectures using an electronic voting system", Journal of Computer Assisted Learning, 20, 81-94.

Elliott, C., (2003), "Using a Personal Response System in Economics Teaching”, International Review of Economics Education, 1, 80-86. DOI 10.1016/S1477-3880(15)30213-9

Davis, S., Connolly, A. and Linfield, E., (2009), "Lecture capture: making the most of face-toface learning", Engineering Education, 4(2), 4-13. 
Elliott, C and Neal, D., (2016), "Evaluating the use of lecture capture using a revealed preference approach", Active Learning in Higher Education, 17(2), 1-15. DOI 10.1177/1469787416637463

Flores, N. and Savage, S.J, (2007), "Student demand for streaming lecture video: empirical evidence from undergraduate economics classes", International Review of Economics Education, 6(2), 57-78. DOI 10.1016/S1477-3880(15)30103-1

Freeman, M., Bell, A., Comerton-Forde, C., Pickering, J., and Blayney, P., (2007), "Factors affecting educational innovation with in class electronic response systems", Australasian Journal of Educational Technology, 23, 149-170. DOI 10.14742/ajet.1262

Goffe, W. L., and Kauper, D., (2014), "A survey of principles instructors: Why lecture prevails", Journal of Economic Education, 45(4), 360-375. DOI 10.1080/00220485.2014.946547

Graham, M., (2014), "Social media as a tool for increased student participation and engagement outside the classroom in higher education", Journal of Perspectives in Applied Academic Practice, 2(3), 16-24. DOI 10.14297/jpaap.v2i3.113

Hannay, M. and Newvine, T., (2006), "Perceptions of distance learning: a comparison of online and traditional learning", Journal of Online Learning and Teaching, 2(1).

Howsen, R. and Lile, S., (2008), "A comparison of course delivery methods: an exercise in experimental economics", Journal of Economics and Finance Education, 7(1), 21-28. DOI 10.2139/ssrn.979091

Jones, C. and Olczak, M., (2016), "The impact of lecture capture on student performance", Australasian Journal of Economics Education, 13(1), 13-29.

Junco, R., Elavsky, C. M. and Heiberger, G., (2013), "Putting Twitter to the test: Assessing outcomes for student collaboration, engagement and success", British Journal of Educational Technology, 44(2), 273-287. DOI 10.1111/j.1467-8535.2012.01284.x

Junco, R., Heiberger, G., and Loken, E., (2011), "The effect of Twitter on college student engagement and grades", Journal of Computer Assisted Learning, 27(2), 119-132.

DOI 10.1111/j.1365-2729.2010.00387.x

Kassens-Noor, E., (2012), "Twitter as a teaching practice to enhance active and informal learning in higher education: The case of sustainable tweets", Active Learning in Higher Education, 13(1), 9-21. DOI 10.1177/1469787411429190

Koenig, K., (2010), "Building acceptance for pedagogical reform through wide-scale implementation of clickers", Journal of College Science Teaching, 39(3), 46-50.

Lage, M. J., Platt, G. J., and Treglia, M., (2000), "Inverting the classroom: A gateway to creating an inclusive learning environment", Journal of Economic Education, 31(1), 30-43.

DOI $10.2307 / 1183338$ 
Laurillard, D., (2013), Rethinking university teaching: A conversational framework for the effective use of learning technologies, New York, NY: Routledge. ISBN 9780415803878

Mann, S. and Robinson, A., (2009), "Boredom in the lecture theatre: an investigation into the contributors, moderators and outcomes of boredom amongst university students", British Educational Research Journal, 35(2), 243-258. DOI 10.1080/01411920802042911

Manochehr, N-N., (2006), “The Influence of Learning Styles on Learners in E-Learning Environments: an Empirical Study", Computers in Higher Education Economics Review, 18(1), $10-14$.

Means, B., Toyama, Y., Murphy, R., Bakia, M. and Jones, K., (2010), "Evaluation of EvidenceBased Practices in Online Learning: A Meta-Analysis and Review of Online Learning Studies", U.S. Department of Education Office of Planning, Evaluation, and Policy Development.

Middleditch, P. and Moindrot, W, (2015a), "Using classroom response systems for creative interaction and engagement with students", Cogent Economics and Finance, 3, 1119368. DOI 10.1080/23322039.2015.1119368

Middleditch, P. and Moindrot, W, (2015b), "Using technology to enhance the student experience in a large cohort settings: evidence from a journey of innovation at the University of Manchester", Journal of Perspectives in Applied Academic Practice, 3(2), 58-71. DOI 10.14297/jpaap.v3i2.151

Olczak, M., (2014), "Evaluating the impact of a web-based resource on student learning", International Review of Economics Education 16, 156-169. DOI 10.1016/j.iree.2013.10.008

Pezzino, M., (2016), "Understanding strategic competition using numerical simulations and dynamic diagrams in Mathematica", International Review of Economics Education, 22, 34-47. DOI 10.1016/j.iree.2016.03.002

Raymond, F., Raymond A. and McCrickard, M., (2008), "Stuck Behind the Math: Just How Helpful Can One Expect Technology to be in the Economics Classroom?", International Review of Economics Education, 7, 62-102. DOI 10.1016/S1477-3880(15)30094-3

Roach, T., (2014), "Student perceptions toward flipped learning: New methods to increase interaction and active learning in economics", International Review of Economics Education, 17, 74-84. DOI 10.1016/j.iree.2014.08.003

Savage, S.J., (2009), "The effect of information technology on economic education", Journal of Economic Education, 40(4), 337-53. DOI 10.1080/00220480903237901

Simpson, V. and Oliver, M., (2007), "Electronic voting systems for lectures then and now: A comparison of research and practice", Australasian Journal of Educational Technology, 32, 187208. DOI 10.14742/ajet.1264 
Smith C.M. and Sodano T.M., (2011), "Integrating lecture capture as a teaching strategy to improve student presentation skills through self-assessment", Active Learning in Higher Education, 12(30), 151-162. DOI 10.1177/1469787411415082

Spielmann, C. and Chaudhury, P., (2016), "Let's make a movie! - Introducing economics with a multimedia research project", Journal of Economics Teaching, 1, 16-41.

Stanca, L., (2006), "The effect of attendance on academic performance: Panel data evidence for introductory microeconomics", Journal of Economic Education, 37(4), 251-266.

JSTOR 30042715

Stephenson, J. and Cortinhas, C., (2013), "Creative uses of in-class technology", in The Handbook for Economics Lecturers (chapter edited by Latreille, P.), The Economics Network.

Taplin R.H., Low, L.H. and Brown, A.M., (2011), "Students' satisfaction and valuation of webbased lecture recording technologies", Australasian Journal of Educational Technology, 27(2), 175-191. DOI 10.14742/ajet.964

Toppin, I.N., (2011), "Video lecture capture (VLC) system: a comparison of student versus faculty perceptions", Education and Information Technologies, 16(4), 383-393.

DOI 10.1007/s10639-010-9140-X

Vazquez, J.J. and Chiang, E.P., (2014), "A picture is worth a thousand words (at least): The effective use of visuals in the economics classroom", International Review of Economics Education 17, 109-119. DOI 10.1016/j.iree.2014.08.006

Watts, M. and Schaur, G., (2011), "Teaching and Assessment Methods in Undergraduate Economics: A Fourth National Quinquennial Survey”, Journal of Economic Education, 42(3), 294-309. DOI 10.1080/00220485.2011.581956

Woo, K, Gosper, M. and McNeill, M., (2008), "Web-based lecture technologies: blurring the boundaries between face-to-face and distant learning", Research in Learning Technology, 16(2), 81-93. DOI 10.1080/09687760802315895

Yamarik, S., (2007), “Does cooperative learning improve student learning outcomes?”, Journal of Economic Education, 38(3), 259-277. JSTOR 30042780 